\title{
INTERthesis
}

DOUTORADO INTERDISCIPLINAR EM CIÊNCIAS HUMANAS - UFSC - FLORIANÓPOLIS - SC - BRASIL

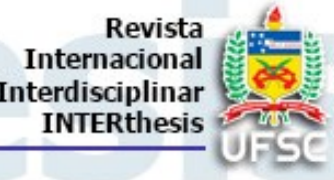

\section{CRIME E VIOLÊNCIA NO BRASIL: REPRESENTAÇÕES SOCIOCULTURAIS NA PÓS-MODERNIDADE}

\section{Resumo:}

Clarice Sohngen ${ }^{1}$ Marcelli Cipriani²

Este artigo visa a abordar algumas representações socioculturais sobre o crime e a violência no Brasil contemporâneo. Nesse sentido, são feitas reflexões acerca do espraiamento do medo coletivo, destacando-se sua relação com a segregação sócio-espacial. Analisa-se, então, a constituição de sociabilidades diferentes em espaços segregados, como elemento que influi nas representações coletivamente produzidas. Por fim, se investiga algumas das respostas sociais à generalização do medo, que perpassam pela produção de discursos reativos à violência que, não raro, também são violentos. Assim, se busca abordar aspectos que se imbricam, quanto aos fenômenos criminais contemporâneos, nas manifestações socioculturais - que é articulada, no trabalho, pelo apontamento de tendências mais amplas do momento histórico - representado pela pós-modernidade - a partir de como se expressam no contexto brasileiro.

Palavras-chave: Representações Socioculturais. Violência. Crime. PósModernidade. Medo.

\section{CRIME AND VIOLENCE IN BRAZIL: SOCIOCULTURAL REPRESENTATIONS IN POST-MODERNITY}

\begin{abstract}
:
This article aims at approaching some of the possible intersections between sociocultural representations of crime and violence in contemporary Brasil. In this sense, it is presented reflections about the spreading of collective fear, highlighting its relationship with socio-spatial segregation. Then, it analyzes the constitution of different sociabilities in segregated spaces, as an element that influences the representations that are collectively produced. Finally, it investigates some of the social responses to the generalization of fear, which are related to the production of discourses that are reactive to violence but are also often violent themselves. Thus, it intends to address aspects where contemporary criminal phenomena are interwoven in sociocultural manifestations - what is articulated by pointing to broader tendencies of the historical moment - represented by postmodernity - from the way they are expressed in the Brazilian context.
\end{abstract}

Keywords: Sociocultural Representations. Violence. Crime. Postmodernity. Fear.

\footnotetext{
1 Professora Titular da Escola de Direito da Pontifícia Universidade Católica do Rio Grande do Sul. Decana Associada da Escola de Direito da Pontifícia Universidade Católica do Rio Grande do Sul. Docente Colaboradora do Programa em Ciências Criminais da Pontifícia Universidade Católica do Rio Grande do Sul, Porto Alegre, RS, Brasil. E-mail: clarice.sohngen@pucrs.br

${ }^{2}$ Mestranda em Ciências Sociais pela Pontifícia Universidade Católica do Rio Grande do Sul, Porto Alegre, Brasil. E-mail: marcellicipriani@hotmail.com
} 


\section{CRIMEN $Y$ VIOLENCIA EN BRASIL: REPRESENTACIONES} SOCIOCULTURALES EN LA POST-MODERNIDAD

\section{Resumen:}

Este artículo apunta a abordar algunas representaciones socioculturales sobre el crimen y la violencia en el Brasil contemporáneo. En este sentido, son propuestas reflexiones sobre expansión del miedo colectivo, destacándose su relación con la segregación socio-espacial. Se analiza, enstonces, la constitución de sociabilidades diferentes en espacios segregados, como elemento que influye en las representaciones colectivamente producidas. Por último, se investiga sobre algunas de las respuestas sociales a la generalización del miedo, que pasan por la producción de discursos reactivos a la violencia que, no raramente, también son violentos. Así, se busca abordar aspectos que se imbrican, en cuanto a los fenómenos criminales contemporáneos, en las manifestaciones socioculturales que es articulada en este trabajo por el apunte de tendencias más amplias del momento histórico - representado por la postmodernidad - a partir de su expresión en el contexto brasileño.

Palabras clave: Representaciones Socioculturales. Violencia. Crimen. Posmodernidad. Miedo.

\section{INTRODUÇÃO}

A expressão da violência é multidimensional, pois acomete variados atores sociais e assume formas diferentes - desde a física, até a psicológica ou a simbólica ${ }^{3}$ - não podendo, por isso, ser tratada como uma espécie de "expressãovalise" (SOUZA, 2008). Por sua vez, a atividade criminosa violenta, sobre a qual se enfoca esse trabalho, é fruto da codificação de uma gama de comportamentos indesejados, a dada sociedade, em certo período histórico ${ }^{4}$. Portanto, também se apresenta como multifatorial, na medida em que possui agentes e circunstâncias típicas muito distintas. Isso implica reconhecer que o crime ocorre de maneira "desagregada", sendo influenciado por aspectos plurais, de diferentes naturezas (SCHABBACH, 2007).

Além disso, tais ocorrências de manifestam pelo espaço urbano heterogeneamente. No Brasil, o espraiamento da violência se dá, em parte, como consequência da distribuição social da paz - que privilegia classes abastadas e

\footnotetext{
${ }^{3}$ Para Bourdieu (2005), a violência simbólica não se expressa por coações físicas ou atos concretos, mas espraia-se de forma silenciosa, se exercendo através de esquemas de percepção, da avaliação e de ação, e que fundamentam aquém das decisões da consciência e os controles da vontade.

${ }^{4}$ De acordo com as abordagens do labeling approach, não há nada inerentemente desviante no crime, pois ele é resultante de uma construção social, que perpassa por assimetrias de poder. Becker (2008), um dos adeptos da também chamada teoria do etiquetamento ou rotulação, propôs investigar o "desvio" como algo que transcende motivações individuais ou particularidades comuns a um grupo desviante, mas como um processo no qual outros atores sociais também precisam ser investigados como aqueles que formulam as regras e suas sanções, e os que são designados para fazê-las ser cumpridas.
} 
cerca bairros populares com um "cordão sanitário repressivo" (SOARES, 2000). Segundo o $12^{\text {a }}$ Anuário de Segurança Pública (FBSP, 2018), a taxa de letalidade policial brasileira é a mais alta do mundo, e os índices de mortes violentas intencionais é mais do que o triplo do considerado endêmico pela Organização Panamericana de Saúde. E, seja quanto a intervenções policiais ou ao crime comum, são as periferias urbanas que, atualmente, estão em posição mais vulnerável à violência (SOUZA, 2008). Somando-se ao recorte territorial, outros elementos influem na probabilidade de ser vitimado por violência no país. Quanto aos homicídios, 92\% da população afetada é masculina (IPEA; FBSP, 2017), 54\% é jovem (entre 15 e 24 anos), e 73\% é negra (FBSP, 2016).

Segundo Garland (2014), as respostas às violências no âmbito do controle do crime dizem respeito não só a considerações criminológicas, mas às forças históricas observadas a partir da segunda metade do século XX. Essas mudanças sociais, econômicas e culturais são características da pós-modernidade e dos realinhamentos políticos que the decorreram, tendo sido vivenciadas com maior ou menor intensidade por todas as democracias industriais ocidentais após a Segunda Guerra Mundial e acentuadas a partir da década de 60. Para o autor, apesar de diferenças nacionais, a chegada da pós-modernidade transformou as condições sociais e políticas sobre as quais se assentava o campo do controle do crime. Ainda, desafiou a legitimidade das instituições, bem como trouxe novos problemas de crime, insegurança e medo.

Apesar da incidência de marcadores sociais sobre a manifestação de qualquer violência, o crime e o medo do crime são amplamente vividos como fatos da vida moderna (GARLAND, 1999), o que faz com que $76 \%$ da população brasileira declare ter medo de morrer assassinada (FBSP, 2016). A sensação de medo coletivo, estimulada pelos crescentes índices de violência urbana - bem como por sua espetacularização midiática - vem se deslocando progressivamente, tornandose quase que ubíqua em algumas metrópoles (SOUZA, 2008). Nesse contexto é que surgem as "fobópoles": grandes cidades nas quais o medo é generalizado - ainda que também matizado de acordo com a classe, a raça, o gênero, a sexualidade e a região de moradia, por exemplo - modelando os hábitos coletivos de deslocamento e lazer, influindo nas formas de habitat, de interação social e de formação dos discursos-padrão sobre a violência urbana (SOUZA, 2008). 
Sendo referidos cotidianamente na pós-modernidade, o crime e o medo do crime tornaram-se riscos que devem, a todo tempo, ser geridos e estimados (GARLAND, 2014). Diante disso, os atores sociais constituíram suas próprias adaptações à disseminação criminal contemporânea, pelo estabelecimento de cuidados rotineiros e de formas de controle social particulares. São essas adaptações coletivas que provocam a importância sociocultural da questão do crime nos tempos atuais, dado que "[...] fornecem a base social para muitas das novas políticas criminais dos últimos anos e moldam a formação cultural - o complexo do crime - que vem crescendo em torno do crime no final do século XX" (GARLAND, 2014, p. 38).

Partindo-se de tal premissa, as reflexões desse artigo se dão em torno de representações sustentadas, no Brasil, em torno do crime e da violência urbana contemporânea. Segundo Porto (2002), embora resultem de experiências individuais, as representações são condicionadas pelo tipo de inserção social do indivíduo ou do grupo que as produzem, expressando visões de mundo que visam a explicar e a dar sentido aos fenômenos - e, com isso, também auxiliando a constituilos. Assim, são imagens que condensam um conjunto de significados, servindo como um sistema de referências que possibilita a interpretação daquilo que ocorre com os atores, assim como a concessão de sentido, por eles, ao inesperado (JODELET, 1985). No âmbito das representações sociais que circundam a violência e a atividade criminosa, propõe-se ressaltar alguns elementos centrais à sua constituição: a segregação sócio-espacial ${ }^{5}$, a constituição de sociabilidades diferentes em espaços segregados, e a produção de discursos sobre o crime - não raro violentos - em resposta à sua tomada como "mal-estar" coletivo.

\section{MEDO DO CRIME E SEGREGAÇÃO SÓCIO-ESPACIAL}

$\mathrm{Na}$ sociedade brasileira, marcada por grandes disparidades, a insegurança urbana e os mecanismos de adaptação à violência perpassam pela segregação sócio-espacial - que, junto ao estabelecimento de locais privilegiados, constitui vizinhanças estigmatizadas (SPOSITO, 2016). Os lugares segregados, que ocupam

5 Em lugar do termo "socioespacial", utiliza-se "sócio-espacial", com base na diferenciação estabelecida por Souza (2007). De acordo com o autor, enquanto o primeiro diz respeito à análise do espaço social (ou substrato), o segundo se ocupa da manifestação das relações sociais no espaço. 
posições inferiores na hierarquia dos espaços metropolitanos, são marcados pela precariedade estatal na oferta de serviços, equipamentos, lazer, cultura, trabalho, acessibilidade a outras partes da cidade, etc. (ALVES, 2016). Porém, tal ausência costuma ser acompanhada da presença substancial do braço armado do Estado: seja pela sujeição privilegiada a patrulhamentos policiais, pela atuação de Unidades de Polícia Pacificadora (UPP's), pelo emprego das Forças Armadas no combate à criminalidade quotidiana ou por outras formas de militarização da questão urbana (SOUZA, 2012).

A segregação sócio-espacial se soma à auto segregação de elites - e, com cada vez mais frequência, de classes médias - que asseguram a fixação de fronteiras através do emprego de mecanismos artificiais, como "muros altos, cercas eletrificadas, guaritas e guardas particulares, cancelas para 'fechar' logradouros públicos e câmeras de TV" (SOUZA, 2006, p. 489) - sistemas de controle e vigilância representativos da ideia de que é possível ter alguma segurança em um mundo de imponderabilidade (SPOSITO, 2016). Portanto, a prática corrente de construção de bairros residenciais de expressivo status social também resulta na produção de áreas diferenciadas nas grandes cidades (CORRÊA, 2016). Assim, a busca por um espaço harmonioso e homogêneo compõe as adaptações ao crime pela sociedade, em especial a que está apta a recorrer a mecanismos de controle não-estatais. Essas tendências, então, impactam as agências de controle do crime como estimulando o serviço de empresas privadas de vigilância e segurança (GARLAND, 2014).

Para Bauman (2003), o processo de isolamento entre diferentes comunidades urbanas teria se iniciado, de forma geral, nos anos 1960, adquirindo progressivo aprofundamento nas décadas subsequentes. No Brasil, ele perpassou pela territorialização das periferias por traficantes de ilícitos, o que se deu no Rio de Janeiro a partir dos anos 1970 e, mais tarde, também passou a ocorrer em outras capitais. Até a década de 80 , moradores de periferias cariocas podiam visitar-se sem esbarrar em maiores mecanismos de controles. A partir de então, tais periferias viveram um progressivo "fechamento" - decorrente da tutela da interação espacial promovida por coletivos criminais - o que intensificou a fragmentação no tecido urbano (SOUZA, 1998). A esse fenômeno soma-se o auto-enclausuramento da elite e das classes médias, que também se aprofunda na década de 70 e prossegue em ritmo febril. Proliferam condomínios exclusivos como o Alphaville, que já detém uma 
área equivalente ao principado de Mônaco - com uma população fixa de, só no Complexo da região metropolitana de São Paulo, 30 mil moradores, e uma população flutuante (funcionários, comerciários, etc.) de mais de 100 mil pessoas (SOUZA, 2006).

Nesse tipo de arranjo territorial, de cunho profundamente intimista, o semelhante (de acordo com a presença de determinados marcadores sociais) é mais facilmente acolhido, enquanto a rejeição do diferente se intensifica desembocando na demonização daqueles que são encarados, pelo grupo homogêneo, como alguém que parece fazer parte "do outro lado" (SOUZA, 1998). Paralelamente, as demandas por lei e ordem também atingem sua máxima potência (SENNETT, 1996), indicando o impacto do anseio social - expresso na cultura pela transformação dos mecanismos institucionais, especialmente os de segurança, e pelo estímulo ao uso de alternativas privadas de proteção à violência. Ao encontro dessas adaptações há a expansão da vigilância e do gerenciamento do crime, assim como o crescimento da comercialização do controle criminal (GARLAND, 2014).

Segundo Garland (2014), tais elementos comporiam algumas das principais transformações no campo da justiça criminal com o advento da pós-modernidade, que passaram a ser observadas especialmente em países ocidentais que seguiram as tendências do capitalismo neoliberal, que partilharam suas influências culturais e que acompanharam os processos de globalização à época. O medo sistemático de ser vitimado por um crime também assumiu dimensão central nas dinâmicas sociais, sendo visto como um problema em si mesmo, dissociado do crime e de sua vitimização. Assim, "políticas específicas têm sido desenvolvidas mais com o objetivo de reduzir os níveis de medo de que de reduzir o crime" (GARLAND, 2014, p. 54).

Porém, o sentimento de medo não pode ser deslocado de suas interfaces com dois mercados: o "da segurança" e o "da violência". No primeiro, se insere a fabricação de armas ou de carros blindados e a disposição da vigilância privada, bem como os condomínios fechados, os shopping centers e outros símbolos de autos segregação de classe (SOUZA, 2008). Ainda, o sistema político-eleitoral, que não raro instrumentaliza o medo coletivo como capital político, e os veículos de informação, que, ao seu turno, o exploram e contribuem para a instituição de pânicos morais (COHEN, 2002). Nesse ínterim, o "mercado da violência" estimula e justifica a expansão do "mercado da segurança", enquanto esse, ainda que 
indiretamente (como pelo desvio e venda ilegal de armas), termina por alimentar aquele (SOUZA, 2008).

Em um arranjo territorial sócio-espacialmente segregado, os mercados da violência e da segurança penetram de forma marcadamente desigual, com, por exemplo, o medo e a insegurança, sendo acionados para controlar a acessibilidade a diferentes lugares e a circulação de pessoas (SPOSITO, 2016). Todavia, a intensificação do isolamento tem por consequência a diminuição de vários tipos de interação sócio-espacial, que tendem a desaparecer ou, então, tornam-se muito mais seletivas. O espraiamento do medo e seu impacto na segregação territorial, bem como a falta de cidadania como valor universal e de prerrogativas políticas para parte considerável das periferias - que, por exemplo, aprenderam que não podem contar com a polícia para sua proteção e permanecem fora da cena pública e política (FELTRAN, 2010) - podem abrir espaço à construção de sentidos diferenciados à sociabilidade urbana, que "legitimam, deslegitimam, institucionalizam e/ou desinstitucionalizam cursos de ação distintos para um mesmo conteúdo, ou cursos de ação semelhantes para conteúdos de sentido contraditório" (MISSE, 1997, p. 11). Portanto, abarcam a construção de variáveis representações socioculturais sobre o crime e da violência, que podem ser dissonantes e até conflitantes entre si.

\section{A COEXISTÊNCIA DE SOCIABILIDADES NO BRASIL CONTEMPORÂNEO}

Como colocado, a segregação sócio-espacial é um dos fatores a demarcar o aparecimento de sociabilidades concomitantes, dado o afastamento das interações entre os indivíduos, o que reforça a dissonância entre seus padrões normativos de comportamentos (MISSE, 1997). Ainda que as sociabilidades que coexistem no país tenham se constituído, historicamente, dentro de processos hierárquicos, elas também já estiveram imbuídas de alguns comportamentos normalizados: por exemplo, com a incorporação da civilidade burguesa pelas camadas sociais excluídas, e pela incorporação das classes médias e elites intelectuais da malandragem, dos valores da preguiça e da "carnavalização da vida" (MISSE, 1997). De acordo com Misse (1997), a partir da década de 70, pode-se identificar um crescente fechamento da sociabilidade cotidiana entre ricos e classe média e entre esses e a população de pessoas pobres, também reforçado pela ausência de áreas comuns para os encontros sociais intercalasses. 
Silva (2004) é um dos autores vem buscando compreender o surgimento recente, no Brasil, de uma "sociabilidade violenta" - um "complexo de práticas sociais que não são coerentes com as rotinas cotidianas estatalmente organizadas" (SILVA, 2004, p. 59). Nesse âmbito, procura investigar a vivência coletiva como conjunto fragmentado em diferentes formas de vida, que podem ser reguladas tanto em torno do Estado, quanto fora de suas normas. $\mathrm{O}$ autor pretende romper com a espécie de etnocentrismo da "suposição de que os conteúdos de sentido que organizam as ações de criminosos e não-criminosos são os mesmos, em ambos os casos expressões subjetivas dos contextos normativos regulados pelo Estado" (SILVA, 2004, p. 66).

Em consonância ao apontado por Misse (1997), Silva (2004) também entende que a integração social, no Brasil, teria desabado mais fortemente em meados dos anos 1970, uma época em que, para além do já apontado, as ações coletivas de moradores da periferia, quanto à mediação normativa entre a população mais pobre e as instituições públicas, começou a se transformar. Feltran (2010) destaca que, ainda que as posições dessas mediações tenham permanecido iguais nas últimas décadas (entre periferia e as instituições), elas mudaram de significado. Por um lado, foram impactadas pela transição do regime militar à democracia, que inseriu (subalternamente) os movimentos sociais periféricos na política institucional; por outro, sofreram incidência das mudanças ocorridas no perfil da população periférica, influenciadas pelas dinâmicas das relações de trabalho após a década de 70 .

Assim, em que pese a relação entre o espaço periférico e o mundo público ter sido, tradicionalmente, marcada pelo conflito, seu percurso e suas formas de contenção ensejaram dispositivos adaptativos diferentes: a luta política, que remonta a demanda pelas prerrogativas de cidadania dos "movimentos sociais" das décadas de 80 e 90; o gerenciamento estatal de populações periféricas, próprio a programas sociais iniciados nos anos 1990; e a violência, como iminência ou ato, na repressão policial atual diante das periferias, e nas próprias ações de sujeitos envolvidos com o "mundo do crime" (FELTRAN, 2010). Essas dinâmicas perpassam pela constituição de diferentes sociabilidades, imbricadas em duas dimensões: nas questões da informalidade no âmbito econômico da sociabilidade (como quanto ao projeto inconcluso do assalariamento brasileiro), e nas questões da (in)civilidade no âmbito sócio-político da sociabilidade (como quanto aos direitos civis) (MISSE, 1997). 
$\mathrm{Na}$ época de ocupação das periferias por migrantes, a promessa de mobilidade social operária se traduziu no sucesso de uma pequena elite periférica que apostou no sobretrabalho e na formação escolar de seus filhos como alavancas de ascensão à classe media. Porém, para a grande maioria dos filhos desses operários, a contrapartida social possibilitada pelo assalariamento nunca chegou: se em 1970 era relativamente fácil conseguir um emprego fabril formal, em 2010 esse emprego era escasso, exigia alta escolaridade, especialização e flexibilidade. Ademais, costumava significar a ocupação de postos pouco estáveis e terceirizados (FELTRAN, 2010). Assim, o local da fábrica que, sob sindicalização crescente, favorecia a construção de identidades e de ações coletivas, se transformou, e aumentou o índice de jovens moradores de periferia que passou a encontrar trajetórias de inserção ocupacional nos limiares entre o formal, o informal e o ilícito (FELTRAN, 2010).

Em paralelo, a cidadania como contrapartida da expropriação econômica e do desenvolvimento do capitalismo foi bastante seletiva no país (MISSE, 1997) e, ainda que as últimas décadas tenham sido marcadas por alguns avanços na redução da desigualdade de renda, esses se deram, consoante colocado por Sousa Santos, (2016), através do consumo, e não mediante a ampliação do acesso à cidadania. Dessa feita, o aumento do poder de compra não foi acompanhado do estabelecimento de condições igualitárias no acesso a serviços públicos, na participação política e no atendimento ofertado pelas instituições, como as policiais e as de justiça - considerando-se, nesse sentido, que a cidadania se desdobra em direitos civis, políticos e sociais. Conforme Carvalho (2002), enquanto os primeiros se referem à vida, à liberdade, à propriedade e à igualdade perante a lei, os segundos dizem respeito à participação do cidadão no governo da sociedade. Os direitos sociais, por sua vez, dependem da máquina administrativa estatal, incluindo o direito à educação, ao trabalho, ao salário justo, à saúde e à aposentadoria (CARVALHO, 2002).

O acesso diferencial à cidadania - seja dada a distribuição espacial da violência, seja devido às profundas desigualdades na justiça social - contribui para que, no país, convivam "referências, conscientes ou pelo menos claramente 'monitoradas', a códigos normativos distintos e igualmente legitimados, que implicam a adoção de cursos de ação divergentes" (SILVA, 2004, p. 73). A articulação de práticas sociais se expressa segundo uma dupla inserção: a de ordem Estatal (como 
por projetos, individuais e coletivos, dotados de diferentes graus de adesão) e a de outra ordem - que pode se configurar sem subordinação à ordem institucional-legal, imersa em um complexo de condutas na qual nem se passa, muitas vezes, pela referência à "ordem pública" (SILVA, 1993). Ambas, todavia, são legítimas (ainda que não necessariamente legais), e coexistem disputando âmbitos da vida social, lançando mão ou não de violências no interior das normativas que abarcam. Um exemplo desses mecanismos pode ser conferido através dos "debates" promovidos pelo Primeiro Comando da Capital (PCC), mecanismos de mediação dos homicídios em periferias paulistas - reconhecidos e procurados por grande parte dessas populações - e segundo os quais só se pode matar através da prévia autorização de membros considerados do grupo (FELTRAN, 2008).

Tais sociabilidades não se tratam, todavia, de universos sociais separados em absoluto, ou em relação aos quais os indivíduos habitam apenas um ou outro. Conforme demonstrado por Feltran (2008), a demarcação das fronteiras entre o "mundo social" e o "mundo do crime" em periferias é amplamente negociável, havendo parte de códigos de conduta que são compartilhados, mas também havendo algumas distinções entre eles, que podem, às vezes se conformar em oposição recíproca. De acordo com o autor, todavia, é a expansão discursiva do crime, e não as ações criminais propriamente ditas, "que faz com que as referências do 'mundo do crime', como representação social e visão de mundo, entrem na disputa por legitimidade social nestes territórios" (FELTRAN, 2008, p. 194). Por outro lado, representações dissonantes são relevantes para a reflexão sobre o papel de diferentes grupos sociais diante de tendências como o endurecimento penal, o populismo punitivo, a legitimidade da violência policial e a criminalização da pobreza - em suma, na criação de adaptações institucionais ao "complexo do crime" (GARLAND, 2014).

\section{O “MAL-ESTAR” COLETIVO E A VIOLÊNCIA COMO DISCURSO LEGÍTIMO}

Segundo pesquisa divulgada pelo Fórum Brasileiro de Segurança Pública, $57 \%$ da população do país concorda com a frase "bandido bom é bandido morto" (FBSP, 2016). Esse percentual é ligeiramente maior para homens (52\%), moradores da região sul (54\%) e pessoas autodeclaradas brancas (53\%) (FBSP, 2016). Já entre os indivíduos que discordam dessa afirmação prevalecem mulheres, pessoas 
autodeclaradas negras, jovens e moradores da região sudeste (FBSP, 2016). Elementos como esses se imbricam na própria construção social da figura de "bandido" - que não necessariamente diz respeito ao cometimento de delitos, mas ao etiquetamento coletivo diante de determinados atores sociais (BECKER, 2008).

llustrando o espaço de disputa exposto pelos dados referidos, traz-se como exemplo que, no ano de 2014, o programa televisivo "Fantástico" veiculou uma reportagem ${ }^{6}$ expondo a execução, no Rio de Janeiro e por dois policiais militares, de um menino de 14 anos, e a tentativa de assassinato de outro, de 15 anos. $\mathrm{Na}$ ocasião, os agentes, durante patrulhamento, visavam a encontrar dois jovens suspeitos de cometer furtos na região e, após visualizarem indivíduos que entenderam ser "suspeitos", os perseguiram, capturaram e os atingiram com disparos. Um deles, apesar de ter sido infligido por dois tiros, sobreviveu. O ocorrido, que ficou conhecido como "Episódio da Sumaré", causou choque em muitos telespectadores, mas recebeu aprovação de inúmeros outros. Na segunda-feira seguinte à exposição dominical da matéria, a Secretaria de Segurança Pública do estado fora inundada por mensagens de apoio à ação da polícia - que, de acordo com essas pessoas, teria agido corretamente, já que para coibir a atuação de supostos bandidos (MENA, 2015).

Tal situação tem eco na análise de Dunker (2015) sobre a unificação do sentimento de mal-estar social, que seria apreendido por nomes que buscam explicar, com perfeição, suas causas e origens. Consoante defende o autor, a tradução coletiva do medo como elemento comum costumaria dar lugar a uma inversão ética entre meios e fins, com a intensificação da insegurança sendo demandada em nome da segurança. Um fenômeno análogo a esse estaria em curso no Brasil, mediante a imperceptibilidade dos indivíduos quanto ao conteúdo violento que também está presente em seus discursos sobre a ascensão da violência (DUNKER, 2015).

O discurso que nomeia e agrega o mal-estar da população em torno de si, que é o que costuma ser veiculado nas mídias tradicionais (podendo, inclusive, ser superexplorado), se imbui de uma cosmética da própria violência - aquilo que, comumente, chamamos de sensacionalismo. Para Garland (2014), os veículos de comunicação também teriam papel relevante no enraizamento da lógica do crime e

6 Ver: http://g1.globo.com/fantastico/noticia/2014/07/cameras-em-carro-da-pm-incriminam-policiaisem-morte-de-menores-no-ri.html Acesso em 08 out. 2017. 
do castigo nas representações populares, contribuindo diretamente com a institucionalização da cultura pós-moderna do "complexo do crime".

Diante do sentimento de "mal-estar", esses discursos captam narrativas plurais, advindas de atores sociais em condições diversas, e as agregam em uma mesma resposta da sociedade. Entretanto, ela mesma pode se calcar na violência imbricando-se, por exemplo, na intolerância contra minorias sociais, no medo de quebra da coesão moral e identitária da "comunidade" (BAUMAN, 2003), no rechaço à corrupção da lei e na demanda por mais autoridade (DUNKER, 2015). Nesses casos, os discursos assumem faces "preventivas" e estigmatizantes, marcadas pela intolerância e exclusão dos espaços de vivência de quem não se enquadra na noção de "harmonia" da "ordem" (BAUMAN, 2003). A unificação do mal-estar também pode ser relacionada com a tendência assumida pelo controle do crime na pósmodernidade, indicada por Garland (2014), quanto ao retorno da vítima ao centro da política criminal.

A posição da vítima nas representações sociais sobre violência é ambígua, e sua conformação igualmente perpassa por marcadores sociais. No que tange à violência contra a mulher, uma pesquisa feita pelo Ipea (2014) apurou que 58\% dos brasileiros concordava, total ou parcialmente, que se as mulheres soubessem se comportar haveria menos estupros. O mesmo estudo apontou que $91 \%$ concordavam, também total ou parcialmente, que homens que batem em suas esposas devem ir para a cadeia. Assim, a culpabilização da vítima pela violência sofrida imbrica-se com a resposta punitiva a essa violência. Ainda, o sentimento de culpa e de vergonha das vítimas, bem como o medo da revitimização, também são elementos relevantes para conformar a baixa notificação de crimes sexuais (DATAFOLHA; FBSP, 2017). Assim, a noção de retorno da vítima ao centro da política criminal não significa que ela deixe de ser descreditada em inúmeras circunstâncias, no âmbito de relações de poder que abarcam demais fatores, como a classe, a raça e o gênero.

Por outro lado, em consonância com o apontado por Garland (2014), essa tendência é percebida na pulverização de legislações com o nome de vítimas - no Brasil, a Lei Maria da Penha, a Lei Menino Bernardo e a Lei Carolina Dieckmann indicando uma mudança no tom emocional da política criminal. Sua figura, diante disso, não só seria utilizada para servir como porta-voz nos debates sobre crime e insegurança, mas também seria engatilhada para a produção de empatia, como 
lembrança de uma tragédia capaz de acometer a qualquer um (GARLAND, 2014). Um dos problemas disso, como demarcado por Garland (2014), é que tal retórica pode servir para forjar um jogo maniqueísta, em que qualquer atenção aos direitos do agressor torna-se intrinsecamente oposta às medidas de respeito às vítimas.

No Brasil, a importância da vítima no debate público pode ser exemplificada na manifestação da deputada federal Keiko Ota (PSB) em 2015, durante votação sobre a redução da maioridade penal. Apesar de um de seus filhos ter sido assassinado, em 1997, por três indivíduos maiores de idade - dois deles policiais militares - a deputada subiu ao plenário vestindo uma camiseta que estampava sua foto. Apelou, então, como uma sobrevivente da violência, pelo urgente fim da suposta impunidade de adolescentes que cometem crimes, e solicitou empatia coletiva diante de sua dor. Daí pode-se perceber que "a presença das vítimas no espaço público de debate, sempre ao lado de políticos ou de autoridades em geral, serve para angariar adesão, através da solidariedade e da formação de consenso, às medidas em sua maioria repressivas pleiteadas por elas" (NASCIMENTO, 2014, p. 25). Com isso pode-se criar, como apontado, uma falsa polarização entre a falta de compaixão com a vítima e a demanda por respostas sociais retributivas, orientadas por uma racionalidade punitiva.

Apesar da generalização do medo do crime e da produção de respostas violentas que pode lhe seguir, não há como ignorar que a criminalidade tem, nas últimas décadas, crescido no país, especialmente no que tange à violência letal. De acordo com a séria histórica formulada pelo Ipea ${ }^{7}$, constituída com base nos dados do Sistema de Informações sobre Mortalidade do Ministério da Saúde (SIM/SM), em 1996 o Brasil contou com 24,78 homicídios por 100.000 habitantes - em números absolutos, foram 38.929 mortes. Em 2016, esse índice chegou a 30,33 - o mais alto de sua história - mediante um total de 62.517 mortes $^{8}$. Porém, a compreensão desses eventos não se confunde com a produção de seu discurso. Como apontado, o crime e o medo do crime estão frequentemente dissociados, e "a tomada de uma palavra na função de nomeação, como diagnóstico unicista do mal-estar, cria uma

\footnotetext{
${ }^{7}$ Disponível em: http://www.ipea.gov.br/atlasviolencia/dados-series Acesso em: 02 set. 2018.

${ }^{8}$ Há que se atentar, nesses dados, ao índice de mortes violentas com causa indeterminada, que são aquelas em que o óbito não foi natural, mas cuja motivação primeira que desencadeou o processo mórbido não pode ser apurada. Assim, a qualidade dos sistemas de informação de mortalidade pode ser medida através da proporção entre o total de mortes violentas e aquelas que não foram esclarecidas. No ano de 1996, a taxa de mortes violentas por causa indeterminada por 100.000 habitantes era, no Brasil, de 4,65. Em 2016, havia subido para 5,0 (IPEA; FBSP, 2018).
} 
estrutura de ficção convergente entre as diferentes narrativas do sofrimento, indexando todas elas em um mesmo fragmento de verdade" (DUNKER, 2015, p. 47).

Os discursos violentos em resposta à violência não são novos no país. Nos últimos sessenta anos, mais de um milhão de pessoas foram linchadas no Brasil (MARTINS, 2015). Além disso, o processo de redemocratização não tem sido eficaz na eliminação de vícios do regime ditatorial, e as esperanças produzidas pela transição para a democracia também não se plasmaram (BAQUERO, 2008). Na transição incompleta para a cultura democrática, se imiscui a crescente desconfiança dos cidadãos nas instituições, que se enraíza tanto no contexto social que dá origem a tal sentimento, como na própria avaliação, feita a partir da experiência, quanto ao desempenho institucional (MOISÉS, 2005). Diante do acesso desigual aos sistemas de justiça e de sua morosidade (MARTINS, 2015), por exemplo, emerge a aceitação populacional da vingança privada, emaranhada na demanda pelo armamento civil.

Em adição, há a defesa de pautas como a redução da maioridade penal e até a pena de morte para crimes graves - que chegam a ser aprovadas por, respectivamente, $87 \%^{9}$ e $43 \%{ }^{10}$ da população brasileira. Representando esses anseios, há conglomerados políticos como a "Bancada da Bala" - frente parlamentar composta por políticos ligados à indústria de armas, ex-policiais e militares de modo geral, e envolvida com a articulação de medidas punitivas. Sua presença, como instância de elaboração de projetos de lei na área da segurança, se aproxima do que Garland (2014) chamou de "politização e o novo populismo punitivo":

O processo de formulação das políticas se tornou profundamente politizado e populista. As medidas políticas são tomadas de maneira tal que aparentam valorizar a vantagem política e a opinião pública, em detrimento da opinião de especialistas e dos resultados de pesquisas. (GARLAND, 2014, p. 57).

O cenário que clama pelo aniquilamento dos tomados como responsáveis pelo mal-estar coletivo e pela corporificação da insegurança comunitária remete à construção da ideia de inimigo interno, que se consolidou nas décadas de ditadura militar, em que a figura do "comunista" e a lógica do combate militarizado ganharam indiscutível força no discurso da segurança pública (NASCIMENTO, 2014). Naquele

9 Disponível em: http://datafolha.folha.uol.com.br/opiniaopublica/2015/06/1646200-87-aprovamreducao-da-maioridade.shtml Acesso em: 08 out. 2017.

${ }_{10}$ Disponível em: http://datafolha.folha.uol.com.br/eleicoes/2014/09/1512693-direita-supera-esquerdano-brasil.shtml Acesso em: 08 out. 2017. 
momento, o país trabalhava com uma concepção belicista do processo social, orientando a política nacional em função da segurança pública. Essa mentalidade, que preconizava o uso da guerra interna ou a eliminação de certos indivíduos como imperativos da segurança nacional, abriu espaço para vertentes diversas de "combate" - que passaram por desde o extermínio físico, até pela demonização psicológica, visando à segregação. Esse processo pode ser aproximado da desumanização que, atualmente, é perpetuada no Brasil com pessoas envolvidas com o crime - a quem é atribuído o estigma do "Outro", que não raro é, também, o indivíduo segregado territorialmente, que compartilha de sociabilidades produzidas em espaços excluídos, e que é vulnerabilizado no contexto do capitalismo contemporâneo.

\section{CONCLUSÃO}

Buscou-se apontar, com esse trabalho, que tendências comuns, típicas ao desenvolvimento histórico de sociedades pós-modernas e à representação cultural que Ihes dá vida, podem ocorrer em lugares diferentes, apesar de existirem importantes particularidades a distinguir seus ambientes político e suas trajetórias sociais (GARLAND, 2014) Esse contexto mais amplo aprofundou um processo de isolamento entre diferentes grupos sociais que, no Brasil, se manifestou pela segregação sócio-espacial e autos segregação de classes, o que implica a redução das interações sociais entre moradores de diferentes áreas urbana, bem como reforça a desigualdade da atuação estatal (SOUZA, 2006), impactando na distribuição heterogênea da violência no espaço urbano (SOUZA, 2008). A distribuição hierárquica e estigmatizante da moradia e da mobilidade, a ausência de convívio entre diferentes grupos sociais e a ânsia pela busca de mecanismos de proteção enseja o espraiamento do medo generalizado, impulsionado pela construção do "Outro" -aquele que encarna a sensação de imprevisibilidade e insegurança (SOUZA, 2008).

Tal fenômeno condiciona a coexistência de diferentes representações socioculturais, que podem perpassar ou não pela legalidade e pelos padrões incutidos pela "ordem pública" e pelo "Estado". Assim, as sociabilidades constituídas no tecido urbano se vinculam à produção de cidades segregadas, imersas nas assimétricas oportunidades de acesso a bens e serviços, o que faz com que uma 
parte dos atores sociais participe precariamente da vida coletiva e da sociedade de consumo de fato, no plano econômico, político e social, ou participe "de forma qualitativamente diferente, porque incompleta, e não apenas quantitativamente desigual" (SPOSITO, 2016, p. 129). Ainda, se estabelecem no caráter diferencial do funcionamento das instituições, que pode transitar entre ser igualitário ou seletivo, eficaz ou ineficaz, violento ou não violento (CARVALHO, 2002).

Esses processos, portanto, são marcados por iniquidades de direitos, que estabelecem novas condições (ou redimensionam condições já existentes), para que parcelas expressivas da população segregada tenha sua vida social imersa no mundo da informalidade ou das ilegalidades (ADORNO; SALLA, 2007). Como resposta às adaptações que se refletem em sociabilidades não normativas, destacou-se a produção de discursos, eventualmente violentos, como reação à insegurança, realçando-se a nomeação do "mal-estar" coletivo através de sua essencialização e homogeneização - a despeito das variações e das assimetrias que perpassam os fenômenos criminais e sua incidência.

Apontou-se que desconstruir a nomeação do mal-estar como violência não significa desconsiderar sua existência na realidade concreta, mas atentar à sua multiplicidade de sentidos, buscando entender "[...] por que e sob quais circunstâncias uma rede de narrativas sobre o sofrimento se torna convergente, produzindo uma espécie de 'grande-mal', que será, a partir de então, impensado e autojustificado" (DUNKER, 2015, p. 48). Assim, demarcou-se a relevância de perceber que as violências se expressam no plural, apesar de matizadas por elementos territoriais, de gênero, idade e raça ou etnia. Pensar abordagens possíveis às intersecções colocadas é, enfim, uma maneira de refutar à padronização da violência e do crime na sociedade como algo uníssono, destacando as assimetrias sociais que perpassam seu desvelamento cotidiano e fragilizando as representações socioculturais que, orientadas em sentido contrário, lançam mão da reprodução da própria violência. 


\section{REFERÊNCIAS}

ADORNO, Sérgio; SALLA, Fernando. Criminalidade organizada nas prisões e os ataques do PCC. Estudos Avançados, São Paulo, v. 21, n. 61, p. 07-29, dez. 2007. Disponível em: http://www.scielo.br/scielo.php?script=sci arttext\&pid=S010340142007000300002\&lng=en\&nrm=iso Acesso em: 03 set. 2018.

ALVES, Glória de Anunciação. A mobilidade/imobilidade na produção do espaço metropolitano. In: SOUZA, Marcelo Lopes de; CARLOS, Ana Fani Alessandri; SPOSITO, Maria Encarnação Beltrão. A produção do espaço urbano: agentes e processos, escalas e desafios. São Paulo: Contexto, 2016.

BAQUERO, Marcello. Democracia formal, cultura política informal e capital social no Brasil. Opinião Pública, Campinas, vol. 14, n. 2, p. 380-413, nov. 2008. Disponível em: http://www.scielo.br/pdf/op/v14n2/05.pdf Acesso em: 10 Out. 2017.

BAUMAN, Zigmund. Comunidade: a busca por segurança no mundo atual. Rio de Janeiro: Jorge Zahar, 2003.

BECKER, Howard Saul. Outsiders: estudos de sociologia do desvio. Rio de Janeiro: Zahar, 2008.

BOURDIEU. Pierre. A dominação masculina. Rio de Janeiro: Bertrand Brasil, 2005.

CARVALHO, José Murilo. Cidadania no Brasil: o longo caminho. 3 ed. Rio de Janeiro: Civilização Brasileira, 2002.

COHEN, Stanley. Folk Devils and Moral Panics: The Creation of the Mods and Rockers. London: Routledge, 2002.

CORREAA, Roberto Lobato. Sobre agentes sociais, escalas e produção do espaço: um texto para discussão. In: SOUZA, Marcelo Lopes de; CARLOS, Ana Fani Alessandri; SPOSITO, Maria Encarnação Beltrão. A produção do espaço urbano: agentes e processos, escalas e desafios. São Paulo: Contexto, 2016.

DATAFOLHA; FÓRUM BRASILEIRO DE SEGURANÇA PÚBLICA. Visível e invisível: a vitimização de mulheres no Brasil, mar. 2017. 
DUNKER, Christian. A violência como nome para o mal-estar. In: KUCINSKI, Bernardo [et al.]. Bala Perdida: a violência policial no Brasil e os desafios para sua superação. São Paulo: Boitempo, 2015, p. 19-26.

FELTRAN, Gabriel de Santis. Fronteiras de tensão: um estudo sobre política e violência nas periferias de São Paulo. 2008. 363f. Tese (Doutorado em Ciências Sociais) - Programa de Pós-Graduação em Ciencias Sociais, Universidade Estadual de Campinas, 2008.

Margens da política, fronteiras da violência: uma ação coletiva das periferias de São Paulo. Lua Nova, São Paulo, n. 79, p. 201-233, 2010. Disponível em: http://www.scielo.br/scielo.php?script=sci arttext\&pid=S010264452010000100009\&lng=en\&nrm=iso Acesso em: 11 out. 2017.

FÓRUM BRASILEIRO DE SEGURANÇA PÚBLICA - FBSP. Anuário brasileiro de segurança pública. Edição X, São Paulo, 2016.

. Anuário brasileiro de segurança pública. Edição XII, São Paulo, 2018.

GARLAND, David. A cultura do controle: crime e ordem na sociedade contemporânea. Rio de Janeiro: Revan, 2014

As contradições da "sociedade punitiva": o caso britânico. Revista de Sociologia e Política, Curitiba, v. 13, p. 58-80, 1999. Disponível em: http://www.scielo.br/pdf/rsocp/n13/a06n13.pdf Acesso em: 8. out. 2017.

INSTITUTO DE PESQUISA ECONÔMICA APLICADA. Sistema de indicadores de percepção social. Tolerância social à violência contra as mulheres. 2014 .

INSTITUTO DE PESQUISA ECONÔMICA APLICADA - IPEA; FÓRUM BRASILEIRO DE SEGURANÇA PÚBLICA - FBSP. Atlas da Violência 2017. Rio de Janeiro, 2017.

. Atlas da Violência 2018. Rio de Janeiro, 2018.

JODELET, Denise. La representación social: Fenómenos, concepto y teoría. In:

MOSCOVICI, Sergei (org.). Psicologia Social. Barcelona: Paidós, 1985. p. 469-474.

MARTINS, José de Souza. Linchamentos: a justiça popular no Brasil. São Paulo: 
Contexto, 2015.

MENA, Fernanda. Um modelo violento e eficaz de polícia. In: KUCINSKI, Bernardo [et al.]. Bala Perdida: a violência policial no Brasil e os desafios para sua superação. São Paulo: Boitempo, 2015, p. 19-26.

MISSE, Michel. Crime Urbano, Sociabilidade violenta e Ordem legítima: comentários sobre as hipóteses de Machado da Silva. Rio de Janeiro, 1997. Disponível em:

https://www2.mppa.mp.br/sistemas/gcsubsites/upload/60/Crime urbano.pdf Último acesso em: 11 out. 2017.

MOISÉS, José Álvaro. A desconfiança nas instituições democráticas. Opinião Pública, Campinas, vol. 11, n¹, mar. 2005. Disponível em:

http://www.scielo.br/pdf/op/v11n1/23694.pdf Último acesso em: 08 out. 2017.

NASCIMENTO, André. Apresentação à edição brasileira. In: GARLAND, David. A cultura do controle: crime e ordem na sociedade contemporânea. Rio de Janeiro: Revan, 2014, p. 07-31.

PORTO, Maria Stela Grossi. Violência a meios de comunicação de massa na sociedade contemporânea. São Paulo em Perspectiva, ano 4, n. 8, p. 152-171, jul/dez 2002. Disponível em: http://www.scielo.br/pdf/soc/n8/n8a07.pdf Acesso em: 01 set. 2018.

SCHABBACH, Letícia Maria. Tendências e preditores da criminalidade violenta no Rio Grande do Sul. 2007. 333f. Tese (Doutorado em Sociologia) - Programa de Pós-Graduação em Sociologia, Universidade Federal do Rio Grande do Sul, Porto Alegre, 2007.

SENNETT, Richard. The Uses of Disorder: Personal Indentity and City Life. Londres: Faber, 1996.

SILVA, Luiz Antônio Machado da. Brasil Urbano: Cenários da Ordem e da Desordem. Rio de Janeiro: Notrya, 1993.

. Sociabilidade Violenta: por uma interpretação da criminalidade contemporânea no Brasil urbano. Sociedade e Estado, Brasília, v. 19, n. 1, p. 5384, jan./jun. 2004. Disponível em: http://www.scielo.br/pdf/se/v19n1/v19n1a04.pdf Acesso em: 11 out. 2017. 
SOARES, Luiz Eduardo. Meu casaco de general: 500 dias no front da segurança pública do Rio de Janeiro. São Paulo: Companhia das Letras, 2000.

SOUSA SANTOS, Boaventura. Brasil: a democracia à beira do caos e os perigos da desordem jurídica. Porto Alegre. Sul21, 22 mar. 2016. Disponível em:

https://www.sul21.com.br/opiniaopublica/2016/03/brasil-a-democracia-a-beira-docaos-e-os-perigos-da-desordem-juridica-por-boaventura-de-sousa-santos/ Acesso em: 01 set. 2018.

SOUZA, Marcelo Lopes de. A prisão e a ágora: reflexões em torno da democratização do planejamento e da gestão das cidades. Rio de Janeiro: Bertrand Brasil, 2006.

Fobópole: o medo generalizado e a militarização da questão urbana. Rio de Janeiro: Bertrand Brasil, 2008.

. Da "diferenciação de áreas" à "diferenciação socioespacial": a "visão (apenas) de sobrevôo" como uma tradição epistemológica e metodológica limitante. Cidades, Presidente Prudente, v. 4, n. 6, p. 101-114, jan./dez., 2007. Disponível em: http://revista.fct.unesp.br/index.php/revistacidades/article/view/573/604 Último acesso em: 16 out. 2017.

Militarização da questão urbana. Lutas Sociais, São Paulo, v. 29, p. 117$\overline{129, \text { jul./dez. 2012. Disponível em: http://www.pucsp.br/neils/downloads/neils-revista- }}$ 29-port/marcelo-lopez-de-souza.pdf Acesso em: 12 out. 2017.

. Tráfico de Drogas e Fragmentação do Tecido Sociopolítico-Espacial no Rio de Janeiro. $2^{\circ}$ Encontro Anual da ANPOCS. Minas Gerais: Caxambu, 1998.

SPOSITO, Maria Encarnação Beltrão. A produção do espaço urbano: escalas, diferenças e desigualdades socioespaciais. In: SOUZA, Marcelo Lopes de; CARLOS, Ana Fani Alessandri; SPOSITO, Maria Encarnação Beltrão. A produção do espaço urbano: agentes e processos, escalas e desafios. São Paulo: Contexto, 2016. 